\title{
Sound Production in the Clownfish Amphiprion clarkii
}

Eric Parmentier, ${ }^{1 *}$ Orphal Colleye, ${ }^{1}$ Michael L. Fine, ${ }^{2}$ Bruno Frédérich, ${ }^{1}$ Pierre Vandewalle, ${ }^{1}$ Anthony Herrel $^{3}$

A lthough clownfish sounds were recorded as early as 1930 (1), the mechanism of sound production has remained obscure.

Yet, clownfish are prolific "singers" that produce a wide variety of sounds, described as "chirps" and "pops" in both reproductive and agonistic behavioral contexts (2). Here, we describe the sonic mechanism of the clownfish Amphiprion clarkii.

We studied sounds (from three males and one female) directed toward conspecifics that approach their sea-anemone hosts. Sound recordings, synchronized with high-speed video (500 fps) coupled ( $n=9$ ) or not $(n=22)$ with an x-ray system, allowed us to quantify movements of skeletal elements (3)

A. clarkii sounds (Fig. 1) are produced in trains of one to eight pulses (means for duration, $26 \mathrm{~ms}$; pulse period, $35 \mathrm{~ms}$; and energy, between about 450 to $800 \mathrm{~Hz}$ ). These parameters do not correspond with typical stridulatory mechanisms (4) and have higher frequency components than swimbladder sounds driven as a forced response to sonic muscle contraction (5).

Sounds $(n=14)$ were typically accompanied by rapid $(<30 \mathrm{~ms})$ movements that include an elevation of the head, lowering of the hyoid bar and anterior part of the branchial basket, a backward movement of the pectoral girdle, and lastly a closing of the lower jaws (movie S1). Synchronization of sound pulses with the video images indicates that sound is produced when the hyoid apparatus is rapidly lowered $\left(23.8 \mathrm{~m} / \mathrm{s}^{2}\right.$, $n=50$ frames) and the mouth simultaneously closed (Fig. 1)

Manipulations of specimens show that low-amplitude elevations of the skull lower the jaws and branchial basket, a phenomenon well known in fish feeding $(3,6)$. Rather than accentuating this movement, a higher- amplitude elevation of the head actually forces the mouth to close by a previously unknown mechanism. fish, supporting our hypothesis. Furthermore, cutting upper and lower jaw teeth resulted in shorter sounds ( 23 versus $48 \mathrm{~ms}, P<0.0001, n=38$ pulses) without the typical low-amplitude highfrequency onset. This result indicates that intact sounds start with teeth collisions (Fig. 1).

Species-specific sounds are produced by all 27 Amphiprion species and appear to be supported at least by interspecific variation in teeth shape. The sonic ligament is present in other members of the damselfish family (7), many of whom produce communication sounds (8). The homologous ligament mechanism is likely involved in sound production throughout this large family and represents a novel skeletal adaptation for a new behavioral function. This functional movement seems to be an exaptation of the feeding mechanism.

References and Notes

1. ]. Verwey, Treubia 12, 305 (1930).

2. E. Parmentier, ]. P. Lagardère, P. Vandewalle, M. L. Fine, Proc. R. Soc. London Ser. B 272, 1697 (2005).

3. S. Van Wassenbergh, A. Herrel, D. Adriaens, P. Aerts, J. Exp. Biol. 208, 4627 (2005).

4. W. N. Tavolga, in Fish Physiology, W. S. Hoar, D. J. Randall, Eds. (Academic Press, New York, 1971), vol. 5, pp. 135-205.

5. F. Ladich, M. L. Fine, in Communication in Fishes, F. Ladich, S. P. Collin, P. Moller, B. G. Kapoor, Eds. (Science Publishers, Enfield, NH, 2006), pp. 3-43.

6. J. Osse, Neth. J. Zool. 19, 290 (1969).

7. M. L. J. Stiassny, ]. S. Jensen, Bull. Mus. Comp. Zool. Harv. Univ. 151, 269 (1987).

8. D. A. Mann, P. S. Lobel, J. Acoust. Soc. Am. 101, 3783 (1997).

9. E.P. is a Scientific Research Worker in Fonds National de la Recherche Scientifique. We thank $P$. Morinière (Aquarium of La Rochelle, France) and D. Barthélemy (Oceanopolis, Brest, France) for kindly giving living specimens of A. clarkii.
Dissections reveal that an unusual sonic ligament is responsible for the rapid lower jaw elevation. The ligament joins the hyoid bar (ceratohyal) to the internal part of the mandible (coronoid process of the articulo-angular) and can be compared to a drawbridge (movie S2). The ligament, acting as a cord, forces the mandible to turn around its articulation during the lowering of the hyoid bar, forcing the mouth to close (Fig. 1). Sound results from the collisions of the jaw teeth, transferring energy to the jaws that are presumably the sound radiator. Transecting the right and left sonic ligaments muted the

\section{Supporting Online Material}

www.sciencemag.org/cgi/content/full/316/5827/1006/DC1 Movies S1 and S2

10 January 2007; accepted 9 February 2007 $10.1126 /$ science. 113975

${ }^{1}$ Laboratoire de Morphologie Fonctionnelle et Evolutive, Institut de Chimie, Bâtiment B6, Université de Liège, B-4000 Liège, Belgique. ${ }^{2}$ Department of Biology, Virginia Commonwealth University, Richmond, VA 23284-2012, USA. ${ }^{3}$ Laboratory for Functional Morphology, Department of Biology, Building C, University of Antwerp, Campus "Drie Eiken," Universiteitsplein 1, 2610 Antwerpen, Belgium.

*To whom correspondence should be addressed. E-mail: E.Parmentier@ulg.ac.be 